\title{
Construção e validação de tecnologia educacional para o atendimento a parada cardiorrespiratória na Atenção Primária
}

Construction and validation of educational technology to care for cardiorespiratory arrest in Primary Care

Construcción y validación de tecnología educativa para la atención de la parada cardiopulmonar en Atención Primaria

\author{
Victoria dos Santos Laqui \\ ORCID: https://orcid.org/0000-0002-7805-512X \\ Hospital Norte do Paraná, Brasil \\ E-mail: vitorialaqui@hotmail.com \\ Gabrielle Rodrigues Munhoz \\ ORCID: https://orcid.org/0000-0002-8321-9862 \\ Universidade Estadual de Maringá, Brasil \\ E-mail: munhozgab@gmail.com \\ Luana Cristina Bellini Cardoso \\ ORCID: https://orcid.org/0000-0001-8460-1177 \\ Universidade Estadual de Maringá, Brasil \\ E-mail: luana.bellini@hotmail.com \\ Fernanda Gatez Trevisan dos Santos \\ ORCID: https://orcid.org/0000-0001-7082-6949 \\ Universidade Estadual de Maringá, Brasil \\ E-mail: fer.gatez@gmail.com \\ Marcelo Silva \\ ORCID: https://orcid.org/0000-0002-0376-0430 \\ Universidade Estadual de Maringá, Brasil \\ E-mail: marceloascencio@gmail.com \\ Rafaely de Cassia Nogueira Sanches \\ ORCID: https://orcid.org/0000-0002-1686-7595 \\ Universidade Estadual de Maringá, Brasil \\ E-mail: rafaely.uem@ gmail.com \\ Gisleine Elisa Cavalcante Silva \\ ORCID: https://orcid.org/0000-0003-0432-198X \\ Universidade Estadual de Maringá, Brasil \\ E-mail: gecsilva@uem.br \\ Cremilde Aparecida Trindade Radovanovic \\ ORCID: https://orcid.org/0000-0001-9825-3062 \\ Universidade Estadual de Maringá, Brasil \\ E-mail: catradovanovic@uem.br
}

\begin{abstract}
Resumo
Objetivo: construir e validar tecnologia educacional para direcionar profissionais de saúde da Atenção Primária à Saúde no atendimento a parada cardiorrespiratória. Método: trata-se de pesquisa metodológica desenvolvida em três fases: revisão de literatura; elaboração das ilustrações, layout, design e textos e validação aparente e de conteúdo, esta última foi realizada entre dezembro/2019 e janeiro/2020. A validação do conteúdo contou com sete profissionais experts no assunto e testado o Índice de Validade de Conteúdo, considerando válido valores iguais ou superiores a 0,80. Ainda, o processo de validação ocorreu em duas rodadas de avaliação: a primeira consistiu na avaliação do material educativo referente ao manejo da ressuscitação cardiopulmonar e a segunda rodada foi a avaliação do material referente as medicações do suporte avançado de vida, obtendo um total de 14 avaliações. Resultados: A tecnologia educativa foi intitulada "Tecnologia educativa para atendimento de pacientes em Parada Cardiorrespiratória na Atenção Primária à Saúde". Os profissionais atribuíram o Índice de Validade de Conteúdo global de 0,89 , o que demonstra que a tecnologia educativa foi considerada validada quanto ao conteúdo e aparência. Conclusão: A tecnologia mostrou-se válida e confiável para utilização dos profissionais de saúde diante atendimento de pacientes em parada cardiorrespiratória nas Unidades Básicas de saúde com um Índice de Validade de Conteúdo global satisfatório.
\end{abstract}

Palavras-chave: Tecnologia educacional; Suporte vital cardíaco avançado; Parada cardíaca; Atenção primária à saúde. 


\begin{abstract}
Objective: to build and validate educational technology to guide Primary Health Care health professionals in the care of cardiorespiratory arrest. Method: this is a methodological research developed in three phases: literature review; elaboration of illustrations, layout, design and texts and apparent and content validation, the latter was carried out between December / 2019 and January / 2020. The content validation counted on seven experts on the subject and tested the Content Validity Index, considering valid values equal to or greater than 0.80 . In addition, the validation process took place in two evaluation rounds: the first consisted of evaluating the educational material related to the management of cardiopulmonary resuscitation and the second round was the evaluation of the material referring to advanced life support medications, obtaining a total of 14 reviews. Results: The educational technology was entitled "Educational technology for the care of patients in Cardiopulmonary Arrest in Primary Health Care". The professionals assigned a global Content Validity Index of 0.89 , which demonstrates that educational technology was considered validated in terms of content and appearance. Conclusion: The technology proved to be valid and reliable for the use of health professionals in the care of patients in cardiac arrest in Basic Health Units with a satisfactory global Content Validity Index.
\end{abstract}

Keywords: Educational technology; Advanced cardiac life support; Heart arrest; Primary health care.

\title{
Resumen
}

Objetivo: construir y validar tecnología educativa para orientar a los profesionales de la salud de la Atención Primaria de Salud en el cuidado de la parada cardiopulmonar. Método: se trata de una investigación metodológica desarrollada en tres fases: revisión de la literatura; elaboración de ilustraciones, maquetación, diseño y textos y validación aparente y de contenido, esta última se realizó entre diciembre / 2019 y enero / 2020. La validación de contenido contó con siete expertos en el tema y probó el Índice de Validez de Contenido, considerando valores válidos iguales o superiores a 0,80. Además, el proceso de validación se realizó en dos rondas de evaluación: la primera consistió en evaluar el material educativo relacionado con el manejo de la reanimación cardiopulmonar y la segunda ronda fue la evaluación del material referido a medicamentos de soporte vital avanzado, obteniendo un total de 14 revisiones. Resultados: La tecnología educativa se denominó “Tecnología educativa para la atención de pacientes en Paro Cardiopulmonar en Atención Primaria de Salud”. Los profesionales asignaron un Índice de Validez de Contenido global de 0.89, lo que demuestra que la tecnología educativa se consideró validada en términos de contenido y apariencia. Conclusión: La tecnología demostró ser válida y confiable para el uso de profesionales de la salud en la atención de pacientes en paro cardíaco en Unidades Básicas de Salud con un Índice de Validez de Contenido global satisfactorio.

Palabras clave: Tecnología educacional; Apoyo vital cardíaco avanzado; Paro cardíaco; Atención primaria de salud.

\section{Introdução}

A Atenção Primária à Saúde (APS) caracteriza-se por um conjunto de ações em saúde individuais, familiares e coletivas que envolvem promoção, prevenção, proteção, diagnóstico, tratamento, reabilitação, redução de danos, cuidados paliativos e vigilância em saúde. É considerada a principal porta de entrada do Sistema Único de Saúde (SUS), bem como é o ponto de comunicação entre as redes de atenção à saúde (RAS), sendo a responsável pela coordenação do cuidado e ordenadora do fluxo dos usuários nos diferentes níveis de complexidade (Brasil, 2017).

Deste modo, o nível primário de atenção à saúde, apresenta as Estratégias de Saúde da Família (ESF) como responsáveis pelos atendimentos de baixa complexidade, com recursos humanos e materiais voltados prioritariamente para a prevenção e promoção da saúde. Seu caráter preventivo, pode levar muitas pessoas a relacionar os atendimentos de urgência e emergência como uma responsabilidade estritamente hospitalar (Prates, 2016).

Neste sentido, o atendimento de urgência/emergência nas Unidades Básicas de Saúde (UBS), não está claramente estabelecido e é repleto de lacunas, dando margem a confusão entre os profissionais responsáveis pela assistência (Laurindo et al., 2019). No entanto, é de responsabilidade da APS o atendimento às urgências e emergências, em ambiente adequado até a transferência/encaminhamento dos pacientes a outros pontos da RAS, mediante a implantação do acolhimento com classificação de risco e vulnerabilidades, tendo em vista a responsabilidade da assistência resolutiva à demanda espontânea e ao primeiro atendimento (Brasil, 2013). Para tanto, é essencial que os profissionais de saúde estejam preparados para agir em situações críticas, como em casos de paradas cardiorrespiratórias (PCR) (Silva, 2014).

A PCR é uma condição clínica de emergência que se não revertida rapidamente pode levar o indivíduo a morte. Tratase de um evento decorrente de uma alteração na função elétrica do coração, o qual passa a bombear de maneira insuficiente, 
causando fibrilação ventricular, taquicardia ventricular, assistolia e/ou atividade elétrica sem pulso (AESP). Durante a assistência de um paciente em PCR o tempo hábil é extremamente importante, destaca-se a importância de oferecer um treinamento para os profissionais e disponibilizar os equipamentos necessários para o uso imediato, pois a cada minuto que a pessoa fica em parada, perde cerca de 10\% de sobrevida (Carvalho et al., 2020; Meira-Junior et al., 2016). Assim, uma manobra de ressuscitação cardiopulmonar (RCP) quando bem desempenhada pode auxiliar a reverter uma parada cardíaca, além do uso de medicações adequadas (American Heart Association, 2017).

Para tanto é preciso sistematizar a atenção prestada, de maneira a otimizar o manejo ao paciente e evitar complicações. A utilização de organogramas e mnemônicos auxiliam o profissional de saúde nesse processo. Tecnologias impressas são instrumentos úteis para descrever assuntos relacionados à saúde e são um recurso viável de utilização diante do seu baixo custo e praticidade na aplicação (Siddharthan et al., 2016).

A disponibilização da tecnologia educativa para o atendimento na RCP construída e validada por meio de método científico poderá contribuir para melhorias na assistência direcionada a este atendimento, facilitando a compreensão acerca das condutas. Ademais, possibilita a realização de estudos futuros que comparem a efetividade de recursos educativos no conhecimento dos profissionais de saúde da APS diante de uma RCP na UBS. Pelo exposto, este estudo teve como objetivo construir e validar uma tecnologia educacional para direcionar os profissionais de saúde da APS no atendimento a PCR.

\section{Metodologia}

Trata-se de pesquisa metodológica desenvolvida em três fases: revisão de literatura; elaboração das ilustrações, layout, design e textos e validação aparente e de conteúdo (Polit \& Beck, 2011).

A primeira fase, revisão bibliográfica, foi realizada no período de julho a setembro de 2019 utilizando as bases: Scientific Electronic Library Online (SciELO) e Biblioteca Virtual em Saúde (BVS), com os seguintes Descritores em Ciências da Saúde (DeCS) combinados por meio do operador booleano AND: "suporte vital cardíaco avançado" (advanced cardiac life support"), "tratamento farmacológico" ("drug therapy"), "fármacos cardiovasculares" (“cardiovascular agents"), "epinefrina" ("epinephrine"), "administração e dosagem" ("administration and dosage"), "suporte vital cardíaco avançado" ("advanced cardiac life support”), "parada cardíaca" (“heart arrest”), "parada cardíaca em adultos”(“adult cardiac arrest”), "parada cardíaca em pediatria" (“cardiac arrest in pediatrics"). Utilizou-se o descritor controlado "parada cardíaca" ("heart arrest"). Foram incluídos estudos publicados no período compreendido entre 2011 a 2019, com o objetivo de abranger os estudos mais recentes na área de interesse.

Após a compilação dos dados obtidos com os artigos selecionados na revisão integrativa, também foram incluídas informações presentes nos protocolos de Suporte Avançado de Vida do Serviço de Atendimento Móvel de Urgência (SAMU) e o Protocolo com a atualização das diretrizes sobre Ressuscitação Cardiopulmonar e Atendimento Cardiovascular de Emergência do American Heart Association. Esta segunda etapa constituiu-se na elaboração da tecnologia educativa. Os conteúdos que a integraram foram baseados nos artigos científicos e literatura especializada na área de urgência e emergência, identificados na revisão.

A terceira fase, realizada entre dezembro/2019 e janeiro/2020 foi a validação aparente e de conteúdo, o qual se examina com precisão um instrumento definido. Esta etapa é fundamental para o processo de elaboração de instrumentos, uma vez que possibilita corroborar se as medidas representadas na tecnologia educativa proposta são realmente válidas e confiáveis (Santos et al., 2019).

Para o processo de validação, foram considerados experts aqueles que apresentassem amplo grau de conhecimento, habilidade e uma experiência profusa na área de urgência e emergência. Deste modo, foram selecionados 15 profissionais, dos quais sete aceitaram participar, sendo seis enfermeiros e um farmacêutico. A escolha ocorreu mediante avaliação do Currículo 
Lattes e uma carta convite foi encaminhada via e-mail abrangendo todos os objetivos da pesquisa.

A priori, os juízes preencheram o Termo de Consentimento Livre e Esclarecido (TCLE) e uma cópia do questionário de avaliação do material educativo contendo inicialmente questões referentes a dados pessoais e profissionais. Posteriormente, o processo de validação ocorreu em duas rodadas de avaliação: a primeira consistiu na avaliação do material educativo referente ao manejo da RCP e a segunda rodada foi a avaliação do material referente as medicações do suporte avançado de vida. Deste modo, obteve-se um total de 14 avaliações. Para além disso, os juízes avaliaram o material quanto a organização geral, estratégia de apresentação, formatação e coerência, características linguísticas, compreensão e estilo da escrita e relevância do material. A avaliação foi realizada por meio de quatro graus de valoração: "totalmente adequado" (1), “adequado" (2), "parcialmente adequado" (3) e "Inadequado" (4) (Polit, Beck, \& Hungler, 2011, Coluci, Alexandre, \& Milani, 2015). Para uma avaliação mais adequada os peritos receberam uma versão digitalizada da tecnologia educativa, com um prazo para devolução de 15 dias corridos.

Para a análise de dados, utilizou-se o Índice de Validade de Conteúdo (IVC), de forma que um índice de concordância a partir de $80 \%$ foi considerado parâmetro de validade (Benevides et al., 2016). O cálculo foi realizado a partir da somatória das respostas "Totalmente adequado" e "Adequado" de cada juiz em cada item do questionário de avaliação e dividiu-se pelo número total de respostas, (IVC: valor da soma de concordância dos itens / $\mathrm{n}^{\circ}$ total de respostas dos itens), os itens que receberam classificação parcialmente adequada e inadequada, foram revisados de acordo com as sugestões dos especialistas (Coluci, Alexandre, \& Milani, 2015).

O estudo foi desenvolvido em consonância com a Resolução n ${ }^{\circ}$. 446/12 do Conselho Nacional de Saúde. E aprovado pelo Comitê Permanente de Ética em Pesquisas Envolvendo Seres Humanos sob parecer $n^{\circ}$ 2.730.919/2018. Todos os participantes assinaram o Termo de Consentimento Livre e Esclarecido, em duas vias.

\section{Resultados}

Participaram como juízes sete profissionais (seis enfermeiros e um farmacêutico) que atuam na assistência e na docência. A média de idade foi de 33 anos, tempo médio de formação de 10 anos e seis meses. Dos sete profissionais, três são doutores, dois mestres e dois especialistas, com experiência em urgência e emergência nas áreas de docência, pré-hospitalar (SAMU), hospitalar e na gestão do serviço de urgência e emergência.

Com relação ao processo de validação do material educativo, verificou-se os seguintes resultados de IVC para as categorias: objetivo da tecnologia apresentou 0,97 ; conteúdo 0,85 ; linguagem 0,98 ; relevância 0,76 ; ilustrações 0,86 ; layout 0,84; motivação 1,00 e Cultura 0,86. Deve-se ressaltar que apenas um item, relativo à relevância do material, apresentou valor de IVC $(0,76)$ abaixo da concordância mínima adotada. No entanto, calculando-se a média do IVC para cada um dos aspectos avaliativos, obteve-se um IVC global de 0,89 , o que significa que a tecnologia educativa foi considerada validada quanto ao conteúdo e aparência pelos especialistas (Quadro 1). 
Quadro 1. Distribuição das análises dos juízes sobre o material educativo segundo os critérios de validação. Maringá, PR, Brasil, 2020.

\begin{tabular}{|c|c|c|c|c|c|}
\hline \multirow[t]{2}{*}{ Itens } & \multicolumn{5}{|c|}{ Scores } \\
\hline & TA & $\mathbf{A}$ & PA & $\mathbf{I}$ & IVC \\
\hline Objetivos & \multicolumn{5}{|c|}{$\mathbf{0 , 9 7}$} \\
\hline São coerentes com as necessidades do público-alvo. & 08 & 06 & 00 & 00 & 1,00 \\
\hline Auxiliara no atendimento da parada cardiorrespiratória. & 06 & 07 & 01 & 00 & 0,93 \\
\hline Pode circular no meio científico da área. & 07 & 07 & 00 & 00 & 1,00 \\
\hline Pode promover mudança no atendimento. & 07 & 06 & 01 & 00 & 0,93 \\
\hline Conteúdo & \multicolumn{5}{|c|}{$\mathbf{0 , 8 5}$} \\
\hline É apropriado ao público. & 11 & 02 & 01 & 00 & 0,93 \\
\hline Claro e objetivo. & 08 & 03 & 03 & 00 & 0,79 \\
\hline Estão cientificamente corretas. & 07 & 04 & 03 & 00 & 0,79 \\
\hline Ressalta a importância do conteúdo. & 06 & 05 & 02 & 01 & 0,79 \\
\hline São variados e suficientes para atingir os objetivos. & 11 & 02 & 01 & 00 & 0,93 \\
\hline Linguagem & \multicolumn{5}{|c|}{$\mathbf{0 , 9 8}$} \\
\hline Informações claras e compreensíveis. & 07 & 06 & 01 & 00 & 0,93 \\
\hline Redação é compatível com o público. & 06 & 08 & 00 & 00 & 1,00 \\
\hline Bem estruturada em concordância e ortografia. & 10 & 04 & 00 & 00 & 1,00 \\
\hline A escrita utilizada é atrativa. & 07 & 07 & 00 & 00 & 1,00 \\
\hline Relevância & \multicolumn{5}{|c|}{$\mathbf{0 , 7 6}$} \\
\hline O material propõe ao aprendiz adquirir conhecimentos. & 10 & 02 & 00 & 02 & 0,86 \\
\hline Aborda os assuntos necessários. & 08 & 03 & 03 & 00 & 0,79 \\
\hline $\begin{array}{l}\text { Pode ser usado como tecnologia para a educação em saúde de profissionais da } \\
\text { atenção básica. }\end{array}$ & 04 & 05 & 05 & 00 & 0,64 \\
\hline Ilustrações & \multicolumn{5}{|c|}{$\mathbf{0 , 8 6}$} \\
\hline São pertinentes com o conteúdo do material. & 10 & 00 & 04 & 00 & 0,71 \\
\hline Estão expressivas e de fácil entendimento. & 08 & 06 & 00 & 00 & 1,00 \\
\hline Layout & \multicolumn{5}{|c|}{$\mathbf{0 , 8 4}$} \\
\hline Está atrativa e bem organizada. & 06 & 06 & 02 & 00 & 0,86 \\
\hline O tamanho das letras é adequado. & 07 & 06 & 01 & 00 & 0,93 \\
\hline O tipo de letra facilita a leitura. & 10 & 03 & 01 & 00 & 0,93 \\
\hline As cores dos textos são pertinentes. & 06 & 05 & 03 & 00 & 0,79 \\
\hline A disposição do texto está adequada. & 05 & 05 & 04 & 00 & 0,71 \\
\hline Motivação & \multicolumn{5}{|c|}{1,00} \\
\hline O conteúdo desperta interesse para a leitura. & 09 & 05 & 00 & 00 & 1,00 \\
\hline O conteúdo está motivador e incentiva a leitura. & 11 & 03 & 00 & 00 & 1,00 \\
\hline Cultura & \multicolumn{5}{|c|}{$\mathbf{0 , 8 6}$} \\
\hline O material está apropriado ao público alvo & 06 & 06 & 02 & 00 & 0,86 \\
\hline IVC GERAL & & & & & $\mathbf{0 , 8 9}$ \\
\hline
\end{tabular}

TA: Totalmente Adequado; A: Adequado; PA: Parcialmente Adequado; I: Inadequado; \%C: Porcentagem de Concordância Fonte: Autores (2020).

No Quadro 1 é importante observar o IVC de cada item em destaque, bem como as pontuações das colunas de totalmente adequado e adequado, pois significam que o conteúdo que foi avaliado é significativo e passível de reprodução tanto em futuras pesquisas como nos serviços de saúde.

Ainda, foram analisadas as sugestões de cada profissional para o aperfeiçoamento do material, acatando-as, tais como: reformulação de layout; substituição ou exclusão de termos; reformulação e inclusão de informações; simplificação e reelaboração de frases, conforme consta no Quadro 2. 
Quadro 2. Modificações no material educativo a partir das sugestões dos juízes. Maringá-PR, Brasil, 2020.

\begin{tabular}{|c|c|c|}
\hline Itens do Material Educativo & Sugestões dos Juízes & Alterações realizadas \\
\hline \multirow[t]{3}{*}{ Conteúdo } & $\begin{array}{l}\text { Acrescentar as referências; corrigir FA para por } \\
\text { FV; incluir valores de Joule; acrescentar - checar } \\
\text { respiração; reorganizar ordens do quadro de } \\
\text { compressões; identificar o } 1^{\circ}, 2^{\circ} \text { e } 3^{\circ} \text { choques para } \\
\text { favorecer a sequência lógica; destacar que após o } 1^{\circ} \\
\text { choque teoricamente está se obtendo acesso } \\
\text { endovenoso; inserir lidocaína como antiarrítmico de } \\
\text { segunda escolha e modificar o tempo de medicação } \\
\text { para } 3 \text { - } 5 \text { minutos; verificar a dose máxima para } \\
\text { Lidocaína e Amiodarona e indicar quantas vezes } \\
\text { pode-se repetir a administração de Amiodarona. }\end{array}$ & $\begin{array}{l}\text { As alterações } \text { solicitadas foram } \\
\text { acatadas. }\end{array}$ \\
\hline & $\begin{array}{l}\text { Realizar treinamento com o público alvo; informar } \\
\text { como utilizar um DEA. }\end{array}$ & Não aplicável \\
\hline & $\begin{array}{l}\text { Informar o uso de Epinefrina a cada } 2 \text { a } 4 \text { minutos } \\
\text { de acordo com o Protocolo Internacional. }\end{array}$ & $\begin{array}{l}\text { Foi optado por manter o intervalo de } 3 \\
\text { a } 5 \text { minutos como preconizado pela } \\
\text { American Heart Association. }\end{array}$ \\
\hline Linguagem & $\begin{array}{l}\text { Alterar os quadros que explicam sobre o uso de } \\
\text { medicamentos, descrevendo o nome do } \\
\text { medicamento em letra maiúscula, indicar a via de } \\
\text { administração após o nome do medicamento com } \\
\text { um tamanho um pouco menor e repetida após a } \\
\text { indicação da dose para gerar contraste; Acrescentar } \\
\text { a informação "intercalada com Epinefrina" após a } \\
\text { orientação de repetir a Amiodarona na dose de } 150 \\
\text { mg; indicar o intervalo entre as compressões } \\
\text { também em minutos ( } 3 \text { a } 5 \text { minutos) especificar que } \\
\text { a Lidocaína deve ser feita "em bolus" ou diluída; } \\
\text { acrescentar legenda em abreviações. }\end{array}$ & $\begin{array}{l}\text { As alterações } \text { solicitadas foram } \\
\text { acatadas }\end{array}$ \\
\hline Ilustrações & Acrescentar uma imagem de um DEA & Não aplicável \\
\hline Layout & $\begin{array}{l}\text { Manter quadros coloridos, porém letras pretas; } \\
\text { ampliar o espaço para definição sobre } \\
\text { administração e doses de medicamentos e adequar } \\
\text { formatação dos quadros. }\end{array}$ & $\begin{array}{lll}\text { As alterações } & \text { solicitadas foram } \\
\text { acatadas } & & \end{array}$ \\
\hline
\end{tabular}

Fonte: Autores (2020).

No Quadro 2 nota-se que as principais correções solicitadas pelos avaliadores foram acatadas e justificadas, exceto quando a sugestão não era aplicável.

Após a avaliação dos juízes e a realização das alterações solicitadas, a tecnologia educativa elaborada foi intitulada “Tecnologia educativa para atendimento de pacientes em Parada Cardiorrespiratória na Atenção Primária à Saúde” (Figura 1). 
Figura 1. Apresentação do material educativo com orientações para profissionais de saúde da Atenção Primária à Saúde sobre o atendimento na Ressuscitação Cardiopulmonar em Adulto. Maringá, PR, Brasil, 2020.

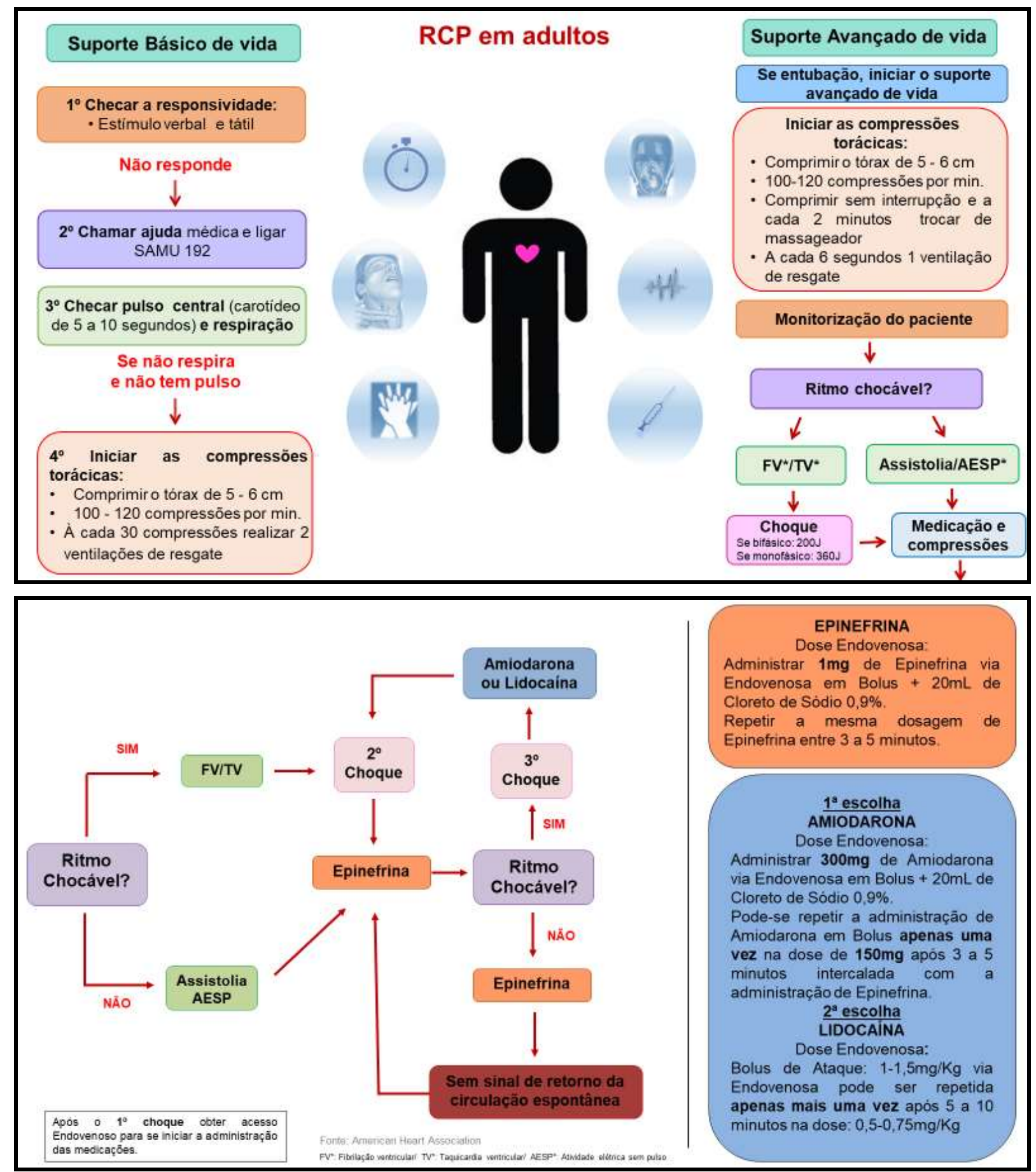

Fonte: Autores (2020).

No esquema da Figura 1 é importante observar o manejo adequado que deve ser seguido em caso de uma parada cardiorrespiratória. A coluna à esquerda demonstra o suporte básico de vida, que deve ser seguido quando a PCR ocorre na atenção primária ou em lugares públicos. O ideal é que o profissional ou pessoa responsável pelo suporte básico siga todas orientações até a chegada do suporte avançado de vida. 


\section{Discussão}

No presente estudo, elaborou-se e validou-se um material educativo para auxiliar os profissionais de saúde da APS no atendimento a PCR. Tecnologias educativas são essenciais no que tange ao processo educativo em saúde, uma vez que são um instrumento de coletivização do conhecimento, promoção da saúde e prevenção de afecç̃os (Santos et al., 2017).

Neste estudo, por meio do diagnóstico prévio das necessidades dos profissionais da APS; o emprego de um referencial para o esquema gráfico, linguagem e layout; a validação por especialistas de diversas áreas e experiências, proporcionaram uma ferramenta de fácil acesso e compreensão na assistência aos pacientes em parada cardiorrespiratória nas UBS.

O processo de validação do material educativo visou a participação de juízes experts de diferentes áreas, pois assim o material ficaria em conformidade com a realidade e o conhecimento seria concreto, prático e adequado. O uso da tecnologia impressa auxilia no direcionamento e padronização das ações em casos de PCR na UBS. A linguagem utilizada na construção do material educativo foi fundamental para o aproveitamento desse conhecimento (Wild, 2017).

Assim, a maioria dos especialistas avaliou todos os itens como totalmente adequado e adequado, demonstrando ter validade de conteúdo e evidenciando que a tecnologia educativa apresenta método de qualidade, cumprindo desta forma com o objetivo do estudo. A validação da aparência foi considerada satisfatória pelos especialistas, apenas com algumas ressalvas. Em relação ao conteúdo avaliado, revelou-se um valor do IVC significativo com nível notável de concordância, o que sugere que a tecnologia educativa é representativa. O uso de validade aparente e de conteúdo por profissionais especialistas tem sido realizado por pesquisadores na área de validação. Outros estudos sobre tecnologias educativas foram encontrados com valores de IVC semelhantes (Moura et al., 2019; Galindo-Neto et al., 2019).

Observou-se que outros estudos que validaram tecnologias educativas impressas também utilizaram o IVC para validação de conteúdo e passaram por ajustes até a elaboração da versão final validada, enfatizando, dessa forma, a importância da realização dessa etapa para o desenvolvimento de um material qualificado (Teles et al., 2014; Lima et al., 2017). Deste modo, apesar de o IVC global ter demonstrado significância $(0,89)$, os juízes do atual estudo propuseram mudanças consideráveis para o aperfeiçoamento do material. Ademais, todos concordaram com sua aplicabilidade na prática.

No que tange à linguagem, esta pode contribuir ou dificultar a compreensão da mensagem veiculada. A preparação textual deve ser acessível ao nível educacional e cultural das pessoas a serem beneficiadas pelo material construído. Esta deve receber atenção, portanto, a participação de profissionais de diversas áreas pode aumentar a credibilidade e a aceitação das tecnologias educativas (Rodrigues et al., 2020).

Estudo prévio realizado com profissionais de saúde da APS demonstrou que a maior dificuldade dos profissionais é o despreparo da equipe, relacionada a falta de treinamento em PCR. Ainda, as respostas obtidas demonstraram vários conteúdos de interesse, no qual, três temas se sobressaíram: Parada Cardiorrespiratória; Obstrução de Via Aérea por Corpo Estranho (OVACE) e Crise convulsiva. Este mesmo estudo serviu de sustentação para a construção da tecnologia educativa, visto que a pesquisa é voltada a mesma população alvo. Deste modo, o desenvolvimento da tecnologia educativa e sua validação demonstraram ser um importante instrumento para maior qualidade no atendimento de PCR no município (Omena et al., 2019).

No que tange ao processo de RCP é necessário um atendimento rápido e ágil, e dispor de um material educativo que possa auxiliar no manejo do paciente, tornando as chances de sobrevida muito maiores. Salienta-se o papel do farmacêutico diante de uma situação de urgência e emergência, mesmo com escassez da literatura com poucos artigos que abordem tal assunto, existem estudos que evidenciam que contar com um profissional farmacêutico no serviço de pronto atendimento favorece a redução de custos, além de priorizar o cuidado ao paciente, principalmente com relação a terapia medicamentosa, evitando possíveis erros e identificando reações adversas (Siqueira et al., 2018). 
Deste modo, o presente estudo possui como limitação a não validação junto ao público-alvo, o que impossibilita medir o entendimento e a efetividade do conteúdo contido na tecnologia educativa, bem como a dificuldade em comunicação com os juízes e a participação destes no processo de validação do material educativo. No entanto, a participação dos mesmos eleva a confiabilidade e a aceitação da tecnologia educativa, principalmente entre os profissionais de saúde que se beneficiarão com o material.

\section{Conclusão}

A tecnologia educativa nomeada de "Tecnologia educativa para atendimento de pacientes em Parada Cardiorrespiratória na Atenção Primária à Saúde" foi construída a partir de um estudo prévio sustentado nas necessidades elencadas pelos profissionais de saúde e a fundamentação teórica sobre a temática abordada. Esta mostrou-se válida e confiável para utilização dos profissionais de saúde diante do atendimento a pacientes em parada cardiorrespiratória nas Unidades Básicas de saúde com um IVC global satisfatório de 0,89.

Devido à importância do assunto, torna-se necessário o desenvolvimento da tecnologia educativa em saúde realizada de forma coerente, didática e atrativa para o atendimento de qualidade. O material educativo tem como intuito colaborar e auxiliar, quando necessário, na prática de reanimação cardiopulmonar sendo uma ferramenta para a educação em saúde, que pode auxiliar no processo ensino-aprendizagem do profissional de saúde da atenção primária, promovendo a aquisição e o aprimoramento de competências no atendimento de qualidade.

\section{Agradecimentos}

O presente trabalho foi realizado com apoio da Coordenação de Aperfeiçoamento de Pessoal de Nível Superior Brasil (CAPES) - Código de Financiamento 001.

\section{Referências}

American Heart Association (2019). About Cardiac Arrest [internet]. https://www.heart.org/en/health-topics/cardiac-arrest/about-cardiac-arrest.

Benevides, J. L., Coutinho, J. F. V., Pascoal, L. C., Joventino, E. S., Martins, M. C., Gubert, F. A., \& Alves, A. M. (2016). Development and validation of educational technology for venous ulcer care. Rev esc enferm USP, 50(2), 306-312. 10.1590/S0080-623420160000200018

Brasil (2013). Manual instrutivo da Rede de Atenção às Urgências e Emergências no Sistema Único de Saúde (SUS). Brasília: Editora do Ministério da Saúde.

Brasil (2017). Portaria $n^{\circ}$ 2.436, de 21 de setembro de 2017. Aprova a Política Nacional de Atenção Básica, estabelecendo a revisão de diretrizes para a organização da Atenção Básica, no âmbito do Sistema Único de Saúde (SUS). Brasília, DF: Ministério da Saúde.

Carvalho, S. S., Costa, J. O., Santos, S. L., Rocha, F. S., Fonseca, S. S. S., \& Silva, N. C. (2020). Conhecimento de enfermeiros intervencionistas em urgência frente à parada cardiorrespiratória. Research, Society and Development, 9(7), e80973721. 10.33448/rsd-v9i7.372

Coluci, M. Z. O., Alexandre, N. M. C., \& Milani, D. (2015). Construction of measurement instruments in the area of health. Ciênc saúde coletiva, 20(3), 925936. 10.1590/1413-81232015203.04332013

Galindo-Neto, N. M., Alexandre, A. C. S., Barros, L. M., Sá, G. G. M., Carvalho, K. M., \& Caetano, J. Á. (2019). Creation and validation of an educational video for deaf people about cardiopulmonary resuscitation. Rev Lat-Am Enferm, 27, e3130. 10.1590/1518-8345.2765.3130

Laurindo, M. V., Ribeiro, L. M. L., Lima, P. S., Bastos, E. C. B., Costa, A. N. B., Vasconcelos, F. F., \& Rocha R. R. (2019). A importância de adaptar as unidades básicas de saúde para o atendimento de urgências e emergências de menor complexidade. Braz J Health Review, 2(3), 1688-1709. http://www.brazilianjournals.com/index.php/BJHR/article/view/1434/1551

Lima, A. C. M. A. C. C., Bezerra, K. C., Sousa, D. M. N., Rocha, J. F., \& Oriá, M. O. B. (2017). Construção e validação de cartilha para prevenção de transmissão vertical do HIV. Acta Paul Enferm, 30(2), 181-189. 10.1590/1982-0194201700028

Meira-Júnior, L. E., Souza, F. M., Almeida, L. C., Veloso, G. G. V., \& Caldeira, A. P. (2016). Avaliação de treinamento em suporte básico de vida para médicos e enfermeiros da atenção primária. Revista Brasileira de Medicina de Família e Comunidade, 11(38), 1-10. 10.5712/rbmfc11(38)1231

Moura, J. R., Silva, K. C., Rocha, A. E., Santos, S. D., Amorim, T. R., \& Silva, A. R. (2019). Construção e validação de cartilha para prevenção do excesso ponderal em adolescentes. Acta Paul Enferm, 32(4), 365-373. 10.1590/1982- 0194201900051 
Research, Society and Development, v. 10, n. 3, e34510313321, 2021

(CC BY 4.0) | ISSN 2525-3409 | DOI: http://dx.doi.org/10.33448/rsd-v10i3.13321

Omena, M. B. S. F., Radovanovic, C. A. T., Gil, N. L. M., Sanches, R. C. N., Artico, G. A., \& Oliva A. P. V. (2019). Educational intervention concerning urgency and emergency in Primary Health Care. O Mundo da Saúde, 43(3), 586-600. 10.15343/0104-7809.20194303586600

Polit, D. F., \& Beck, C. T. (2011). Fundamentos da pesquisa em enfermagem: avaliação de evidências para a prática de enfermagem. $7^{\mathrm{a}}$ ed. Porto Alegre: Art Med.

Polit, D. F., Beck, C. T., \& Hungler, B. P (2011). Fundamentos de pesquisa em enfermagem: métodos, avaliação e utilização. Porto Alegre: Artmed.

Prates, V. S. (2016). Atendimentos de urgência e emergência na atenção primária em saúde: a organização de um projeto de educação permanente. 26f Trabalho de Conclusão de Curso (Especialização em Informação Científica e Tecnológica em Saúde) - Instituto de Comunicação e Informação Científica e Tecnológica em Saúde, Fundação Oswaldo Cruz, Rio de Janeiro.

Rodrigues, L. N., Santos, A. S, Gomes, P. P. S., Silva, W. C. P., \& Chaves, E. M. (2020). Construção e validação de cartilha educativa sobre cuidados para crianças com gastrostomia. Rev Bras Enferm, 73(3), e20190108. 10.1590/0034-7167-2019-0108

Santos, E. C., Silva, S. V. V., Silva, A. M. N., Silva, L. B., Costa, R. P., \& Mandú, E. N. T. (2017). Capacitação em primeiros socorros para equipes de saúde da Atenção Básica: Relato de Experiência. Ciênc cuid saúde, 16(2). 10.4025/cienccuidsaude.v16i2.36909

Santos, S. B., Machado, A. P. A., Sampaio, L. A., Abreu, L. C., \& Bezerra, I. M. P. (2019). Sífilis Adquirida: construção e validação de tecnologia educativa para adolescentes. Journal of Human Growth and Development, 29(1), 65-74. 10.7322/jhgd.157752

Siddharthan, T., Rabin, T., Canavan, M. E., Nassali, F., Kirchhoff, P., Kalyesubula, R., \& Knauf, F. (2016). Implementation of patient-centered education for chronic disease management in Uganda: an effectiveness study. PLoS One, 11(11), e0166411. 10.1371\%2Fjournal.pone.0166411

Silva, V. M. S. (2014). A importância da capacitação no atendimento a parada cardiorrespiratória da equipe de uma unidade básica de saúde. 33f. Trabalho de Conclusão de Curso (Especialização) - Universidade Federal de Santa Catarina, Florianópolis.

Siqueira, R. M. P., Andrade, S. M. B., Cardoso, L. M. L., \& Cavalcante, A. L. C. (2018). A participação do farmacêutico na identificação ou monitoramento de reações adversas a medicamentos no brasil: uma revisão integrativa. Essentia (Sobral), 19(1), 86-94. http://essentia.uvanet.br/index.php/ESSENTIA/article/view/172

Teles, L. M. R., Oliveira, A. S., Campos, F. C., Lima, T. M., Costa, C. C., Gomes, L. F. S., \& Damasceno, A. K. C. (2014). Construção e validação de manual educativo para acompanhantes durante o trabalho de parto. Rev Esc Enferm USP, 48(6), 977-984. 10.1590/S0080-623420140000700003

Wild, C. F. (2017). Validação de uma cartilha como tecnologia educacional com vistas à prevenção da dengue. 168f. Trabalho de Conclusão de Curso (Especialização) - Universidade Federal de Santa Maria. 